time over possible motives for the delay in notifying Thèze - who with Yaniv had uncovered the alleged misconduct independently - and the institute of the allegations.

Kourilsky defends his action, however, saying that a tearful Rebello only agreed to tell him and Coutinho about the misconduct if they "swore to secrecy". He adds that they waited until she brought them proof before proceeding. Nonetheless, Pasteur documents describe the delay as "regrettable", and say that it "inflated" the misconduct incident.

Kourilsky also claims that the first enquiry found "serious malfunctions" in Thèze's laboratory, and says that he hopes that the new enquiry will "clarify" matters. But the institute has declined to comment on the exact nature of the alleged "malfunctioning" until the second enquiry has been completed.

In a written statement to the institute, Thèze dismisses such claims, and criticizes the first enquiry for giving "too much weight" to "allegations formulated by individuals implicated by the enquiry".

One allegation by Thèze's critics is that he failed to oversee his laboratory in Paris properly because of his prolonged absence as director of the Institut Pasteur in Lyons. But a formal evaluation of his laboratory in April 1992 concluded that it was nonetheless running smoothly.

Both François Gros, a former director of the Paris institute, and Jean-Paul Aubert, director of the laboratory of cellular physiology, have said that it was "normal" for Thèze to have delegated the running of his laboratory while working in Lyons.

Aubert has said the institute should have thanked Thèze for taking on the "difficult and risky" job of running the Lyons institute, instead of "making trouble" for him over a "secondary question".

Some claim that the charges against Thèze are linked to the local resentment generated in Lyons by his efforts to introduce reforms aimed at addressing longstanding criticism that it carried out too much commercial biomedical analysis, and not enough fundamental research.

Thèze was fired from his Lyons post in early 1992 after conflict with Michel Robatel, the president of the board of the Lyons institute, although the Ministry of Research and the General Inspectorate of Social Affairs both later favourably assessed his reforms. The Institut Pasteur in Paris subsequently tried to withdraw the Pasteur label from the institute, and the historically strained relationship between the two institutes deepened.

Thèze is confident that the conclusions of the new enquiry, which will report its findings to Schwartz next month, will exonerate his laboratory. Schwartz says that the Jankovic affair is the first case of scientific misconduct to have been brought to his attention since he became director in 1988 .

Declan Butler

\title{
International support urged for biotechnology guidelines
}

London. Government officials in Britain and the Netherlands are leading an attempt to obtain international endorsement of a set of safety guidelines covering the use of genetically engineered organisms and their release into the environment

Both countries are now looking for a possible institutional home for these guidelines. One leading contender is the United Nations Environment Programme (UNEP), which already promulgates similar guidelines covering the environmental impact of new chemicals.

The initiative has raised concern among non-governmental organizations (NGOs) such as the Green Alliance and the World Wide Fund for Nature. They are keen that any such guidelines should be backed by a legal instrument, such as a legally enforceable protocol to the Biodiversity Convention.

The need for an international agreement on biosafety was agreed as part of a plan of action approved by the 1992 UN Conference on the Environment and Development in Rio de Janeiro. "From an NGO position, we cannot accept anything that might sabotage an eventual legal instrument," says Julie Hill, director of the Green Alliance in London. "Guidelines will be useful, but they should eventually become legally binding."

But British and Dutch officials say that, although they share this goal, agreement on a protocol could take ten years or more. It could also run into opposition in principle from developed countries (such as the United States) committed to deregulation.

International endorsement of a common set of technical guidelines would, they claim, be an interim step. "We do not want to present our proposal as an alternative [to any legally binding instrument]," says one British official. "We want to present it as a set of guidelines that people can pick up and introduce straight away."

The draft guidelines have been drawn up by an international group of experts. They build both on domestic experience in the developed countries - particularly Britain and the Netherlands - and on feedback from efforts to stimulate regional debates in a number of developing countries on safety in biotechnology.

As they stand, the proposed guidelines deal with topics such as the assessment and management of risks, establishing national and/or regional focal points responsible for the transfer of information about novel organisms, and helping developing countries to strengthen their own expertise in imposing and evaluating safety procedures.

"The guidelines do not waste time trying to find the perfect solution," says one British official. "It is a 'warts and all' approach, but we hope that it is both a pragmatic and a scientific approach, allowing countries to make the best use of information available at any one time."

Those responsible for drafting the guidelines say they are intended to meet the

\section{IMAGE UNAVAILABLE FOR COPYRIGHT REASONS}

\section{A Nigerian gene bank: safety first.}

concerns of less-developed countries keen, for example, to introduce genetically engineered crops, but uncertain over how to tackle the safety aspects.

At the same time, they say, biotechnology companies in developed countries are equally eager to see an international safety system in place, if only to reduce the likelihood of embarrassing situations that could give the whole industry a bad name.

The proposed guidelines refrain either from addressing the socio-economic impact of biotechnology on countries at different levels of development, or from defining the precise mechanisms for public involvement in the regulatory process. The guidelines also allow individual countries to introduce more stringent safety requirements.

The main political issue now is which international body is best placed to provide the institutional back-up needed to promulgate the guidelines, and in particular to channel to less-developed countries the resources required to implement them.

The development of the proposed guidelines has the backing of the British and Dutch governments. They are now being circulated widely to officials in other countries, and are expected to be discussed in the corridors at a meeting of the Commission of Sustainable Development to be held in New York next week.

The attitude of the NGOs will be important in winning political approval. These remain adamant that a legally binding international commitment will be needed to protect the environment against novel organisms. But most seem prepared to be pragmatic, and to back the proposed moves as an interim measure that is better than nothing.

David Dickson 